\title{
Sospechas de SOSPECHAS, DE SOSPECHAS: MEMORIAL DE UN MILITAR ILUSTRADO A FINALES DEL SIGLO XVIII ${ }^{1}$
}

Ana María Lorandi

Universidad de Buenos Aires, Argentina

alorandi_2000@yahoo.com.ar

\section{Resumen}

El artículo analiza el amplio corpus legal citado en un Memorial destinado al rey, escrito por un militar ilustrado de finales del siglo XVIII, cuyo objetivo es reclamar por la persecución de algunos criollos sospechosos de colaborar con la rebelión de Túpac Amaru. Se trata de detectar las múltiples líneas de conflictos que atravesaban la sociedad peruana después de las grandes rebeliones indígenas. El análisis se apoya en la nueva historia del derecho, que adopta principios de la antropología política y simbólica, donde se conjugan el análisis institucional y la manipulación de la jurisprudencia por parte de actores que buscaban solucionar sus problemas.

Palabras clave: Túpac Amaru, Ilustración, militares, Perú, siglo XVIII.

\section{Abstract}

This article examines the extended legal corpus cited in a Memorial addressed to the king, written by an enlightened soldier at the end of the 18 th century, whose purpose is to protest against the persecution of a few Creoles suspected of collaborating with the Tupac Amaru rebellion. The aim is to detect multiple lines of conflicts that Peruvian society faced after big indigenous rebellions. The analysis is based on a new legal history that adopts the principles of political and symbolic anthropology, where institutional analysis and manipulation of jurisprudence by actors seeking to resolve their problems come together.

Keywords: Túpac Amaru, The Enlightenment, soldiers, Peru, 18th Century. 
En este artículo tratamos de detectar, a través del análisis de un solo manuscrito, las múltiples líneas de conflictos — políticos, institucionales y sociales - que atravesaban la sociedad peruana después de las grandes rebeliones indígenas de Túpac Amaru y de los Catari. El Memorial pone en escena las prácticas y las representaciones de la élite cuzqueña durante la compleja década de 1780. Enfocamos el tema apoyándonos en la nueva historia del derecho, que adopta principios de la antropología política y simbólica, donde se conjugan el análisis institucional y la manipulación de la jurisprudencia por parte de actores que buscaban solucionar sus problemas políticos, sociales y económicos mediante la puesta en obra de la ideología y los valores propios de una época y en un espacio acotados.

Como sabemos, las rebeliones indígenas (y mestizas) se inscribieron en el contexto de las reformas fiscales borbónicas que provocaron rechazo y fomentaron conspiraciones en todos los sectores de la sociedad a lo largo del siglo XVIII ${ }^{2}$. Las reformas implementadas por el visitador José Antonio de Areche — aumento de alcabalas y nuevas aduanas - perjudicaron la economía indígena, un tema ampliamente analizado. Menos atención ha recibido la situación de los hacendados tanto criollos como peninsulares, que también vieron afectadas sus finanzas, en particular los obrajeros que sufrían la competencia de los textiles importados que inundaron los mercados peruanos. La creación del Virreinato del Río de La Plata en 1776 impactó en el erario público del Virreinato del Perú (Céspedes) ${ }^{3}$, pero el comercio interregional entre Cuzco y el Alto Perú no se interrumpió, aunque debieron afrontar mayores costos e implementar nuevas estrategias para burlar los controles estatales (Tandeter y Wachtel).

2 La bibliografía es amplísima, citaremos sólo las obras más conocidas: Fisher; Lewin; O’Phelan (Un siglo).

3 Para matices sobre la opinión de este autor ver el trabajo de Mazzeo. 
En estas circunstancias el criollismo fue tomando un perfil más definido y comenzaron a tejerse alianzas (a veces encubiertas) con algunos poderosos caciques indígenas, como sucedió en el motín de Arequipa y en la abortada conspiración de los plateros del Cuzco, en $1780^{4}$. El rechazo del sector criollo cuzqueño a las reformas tanto fiscales como políticas eclosionó en 1783 cuando, apenas apagado el fuego de la rebelión indígena, los funcionarios borbónicos decidieron ponerlos bajo la lupa. En este clima de sospechas, los hermanos Antonio, Gabriel y Gaspar Ugarte, miembros de una familia de origen español radicada en el Perú desde el siglo XVII, fueron acusados de colaborar subrepticiamente con el cacique de Tinta. Integraban la élite cuzqueña y, aunque ocuparon distintos cargos en el Cabildo, tenían fama de díscolos y soberbios. Protagonistas de varios escándalos públicos, llamaron la atención de las autoridades y cayeron víctimas de la persecución de los funcionarios.

En 1783, siendo alcalde ordinario, Gaspar Ugarte se enfrentó con Gabriel Avilés, comandante de las milicias limeñas que ocuparon Cuzco para sofocar la insurgencia indígena, y con el corregidor de Cuzco, Matías Baulén. Las disputas se desataron por cuestiones de preeminencia simbólica y poder político; pero en realidad ponían al descubierto la rivalidad entre Cuzco y Lima, así como la generalizada disconformidad por la creciente intervención de los militares en los asuntos de la ciudad (Halperin; Marchena).

En el mismo año, Antonio Ugarte se había mezclado en escándalos públicos en los que participaron las monjas del Convento de Santa Catalina - cuya priora, María de la Concepción Rivadeneyra, era su cuñada - y los frailes de Santo Domingo. El motivo fue una cuestión de faldas: la priora de Santa Catalina era la amante del prior de Santo Domingo, y el obispo del Cuzco, Juan Manuel Moscoso, intervino en las disputas, sospechado, a su vez, de ser antiguo amante o pretendiente de la priora.

4 Para la situación en Cuzco, veánse, entre otras obras, las de Carrió; Escandell-Tur; Mörner; O’Phelan ("Aduanas" y "Entre Gálvez y Areche"); Salas de Coloma, y Walker. 
Los detalles de estas intrigas no interesan aquí, pero explican la vulnerable reputación de la familia Ugarte en 1783.

Por otra parte, al comienzo de la rebelión, Túpac Amaru había escrito a Antonio y a su hermano Gabriel, llamándolos "primos" e invitándolos, o más bien conminándolos, a colaborar con sus proyectos. La apelación de primos se debía a los rumores sobre algunas gotas de sangre indígena en las venas de la familia —-mestizaje que ellos negaron enfáticamente-, aunque dio pie para sospechar que hubieran mantenido algún tipo de colaboración con el rebelde.

En el clima de incertidumbre que reinaba en ese momento, todos los personajes que se enfrentaron con los Ugarte se aliaron para acusarlos de promover conspiraciones criollistas e iniciaron una pesquisa destinada a procesarlos $\mathrm{y}$ a aplicarles un castigo ejemplificador que amedrentara cualquier intento de cuestionar la autoridad real. La guerra con Inglaterra y la declaración de independencia de Estados Unidos brindaban argumentos ${ }^{5}$ para tomar medidas preventivas ante el temor de ruptura de los lazos de vasallaje con "la nación dominante" — según expresión de los mismos funcionarios-.

Los Ugarte fueron enviados a Lima y juzgados por la Audiencia, que no encontró mérito en las pruebas enviadas desde Cuzco y los absolvió con la condición de permanecer en la capital del Virreinato. Los denunciantes, no conformes con este fallo tildado de filocriollista, insistieron ante los ministros del rey, quienes ordenaron que los tres hermanos fueran remitidos a la Península. En efecto, vivieron exiliados en España desde 1787 hasta su muerte, sin nuevo proceso (AGI, C29-30; ANP, CD; Bunster y Lorandi).

También un cuñado de los Ugarte, Juan Manuel Fernández Campero ${ }^{6}$, fue víctima de ese exilio forzado, pese a ser nativo español y regalista

5 Informes del ministro conde de Aranda al rey, citado por Lewin (68).

6 Nos referiremos a él como Campero. Fue corregidor de Quispicanchis, luego gobernador de Tucumán (1764-1769). Veáse Lorandi. 
dogmático. Campero había intervenido en la represión de la rebelión indígena, y Areche lo envió a España para que condujera la documentación sobre el proceso a Túpac Amaru. Sin embargo, las sospechas que recayeron sobre sus cuñados afectaron su reputación; no se le permitió regresar a Perú a ocupar el cargo de gobernador de Chuquito, para el que había sido designado en 1780, aunque nunca se inició un proceso formal en su contra.

Desde su exilio en Madrid, Campero se dirigió al rey Carlos IV a fin de solicitar revisara esta medida y para ello escribió un dramático alegato en defensa de su honor, el de su esposa y el de sus cuñados. Este es el contexto en el que debe entenderse el Memorial que analizamos más abajo.

\section{El contexto legal a fines del siglo XVIII}

El Memorial, escrito por Juan Manuel Campero en defensa propia y de la familia Ugarte, es una excelente demostración de la flexibilidad y la ambigüedad en el uso de la legislación durante el Antiguo Régimen, así como del dramatizado lenguaje político de la época. Los historiadores del derecho postulan un nuevo enfoque sobre la jurisprudencia del Antiguo Régimen y reconocen la existencia de un cuerpo legal que orienta los comportamientos sociales y políticos; pero que no los encorseta en un sistema rígido de cumplimiento obligatorio. La "ilegalidad tolerada" — como la define Tau Anzoátegui, utilizando una expresión de Foucault — , interpretada hasta ahora como prueba de desorden o corrupción, es analizada desde una nueva perspectiva que admite modulaciones y matices. La negociación de sentidos nunca estuvo excluida; se planteaba un juego de tensiones entre las autoridades que presionaban para que se cumpliera el cuerpo legal y los súbditos que apelaban en defensa de intereses locales o sectoriales. Las representaciones que solicitaban al rey que revise decisiones adoptan el carácter de un ritual de acatamiento legítimamente formalizado?

7 Para los rituales políticos de poder, véanse Tambiah; Smietniniansky. 
El ritual consistía en apelar a las normas vigentes, así como a las referencias bíblicas, y en disputar en un campo de fuerzas sus respectivos capitales de poder: en nuestro caso, el capital de un grupo de individuos insertos en las prácticas de la cultura colonial frente al poder político de la monarquía borbónica. La existencia de poderes centrales y periféricos con distintas pero, a la vez, superpuestas jurisdicciones y fluctuantes límites de poder dejaba muchos resquicios que eran aprovechados por las relativas autonomías concedidas a los virreinatos, a las ciudades, a las corporaciones y a los individuos. Antonio Hespanha, partiendo de principios elaborados por la antropología de las sociedades complejas que permiten identificar los puntos de fricción o de convergencias entre las normas y las prácticas, sostiene que "si los modelos del orden son plurales también deben serlo las estrategias de resistencia” (14).

La contradicción provocada por la simultaneidad de una teoría jurídica de raíz medieval, todavía vigente, y la nueva política imperial avivó las disputas entre instituciones y agentes sociales por cuestiones de preeminencia y poder. Los intereses públicos y privados se sintieron agredidos y reaccionaron, a veces con violencia, frente a los nuevos métodos de la modernidad; no obstante, a finales del siglo XVIII todavía se apela reiterativamente a las Partidas del rey Alfonso X, promulgadas en el siglo XIII.

En este punto Campero es estrictamente fiel a sus principios, como lo pusimos de relieve al analizar una carta que Campero envió a su hijo Mariano, desde Buenos Aires, antes de emprender el viaje hacia Cuzco, en 1780 (Bunster y Lorandi; Lorandi). La carta es una pieza singular sobre la doctrina del poder del monarca con fuertes ecos del tomismo, enarbolado por los teóricos de la política del siglo XVI, como Vitoria (Guerra; Padgen), así como sobre las obligaciones de los vasallos, cuanto más si eran españoles o criollos. Cabe aclarar que como gobernador de Tucumán había tenido que soportar en 1767 una rebelión de vecinos y esto explica que apenas llegado a Cuzco ofreciera sus servicios militares a las autoridades de la ciudad.

En el Memorial se sintetizan los problemas generales que afectaban durante esos años la marcha de los territorios ultramarinos de la 
monarquía hispana. Trasciende el caso puntual de la controversia entre los personajes que intervienen en la disputa y descubre las fricciones entre distintos estamentos e instituciones. En el escrito de Campero aparecen las líneas de competencia entre el poder civil y el eclesiástico, entre Lima y Cuzco, entre criollos y peninsulares, entre autoridades locales y virreinales, entre civiles y militares.

\section{EL MEMORIAL ${ }^{8}$}

En el encabezado del Memorial, fechado el 15 de agosto de 1790 y dirigido al rey por intermedio del conde de Floridablanca, reza la siguiente leyenda: "Madrid 25 de agosto de 1790. D. Juan Manuel Campero, Coronel de los Reales ejércitos, Gobernador de la Provincia de Chucuito en el Virreinato de Buenos Aires". En el Memorial, Campero sigue las normas de la época, como se revela tanto en la utilización de las Partidas de Alfonso X y las leyes de Castilla y de Indias, promulgadas a lo largo de varios siglos, como por el estilo dramático que imprime a su texto. Dada la profusión de citas legales, se podría aducir que el Memorial no fue obra de su pluma, sino de la de un abogado. Sin embargo, a partir del análisis de múltiples documentos que llevan su firma, escritos en el mismo estilo discursivo, incluyendo además citas bíblicas, creemos que Campero era un hombre versado en leyes, aunque no descartamos que, en esta ocasión, haya recurrido además al asesoramiento de un letrado.

\section{El derecho a la justicia}

Su objetivo es recuperar su honor y el de su familia política, apelando a su derecho a la defensa e invocando la "Pragmática Sanción del sabio Rey d"

8 "Memorial enviado por Juan Manuel Campero al rey por el asunto de sus cuñados Ugarte" (AGI, E 77, no. 86 [1]). Los acontecimientos y controversias aludidos se encuentran en otros documentos que estamos analizando. 
Carlos $3^{\circ}$ del 17 de Abril de 1771 que es la Ley 8 tit 15. Lib 3 de las de Castilla" ("Memorial", f. 2v. ) ${ }^{9}$. La Pragmática se refiere al derecho de justicia de los vasallos fieles en caso de estar vinculados a revueltas o alteraciones del sosiego público, pero también prevé que se "prescriban a los fieles vasallos los medios y modos de no confundirse con los culpados".

Su alegato destaca su condición de "profeso de la orden de Santiago, Coronel de los R ${ }^{\mathrm{es}}$ Ejércitos, Gobernador de la Provincia de Chucuito en el Virreinato de Buenos Aires"10 ("Memorial", f. 1r.) y solicita se admita su reposición en el cargo destacando su participación en la campaña militar contra Túpac Amaru. En virtud de sus méritos fue comisionado para llevar a España los "pliegos" referentes a la rebelión, pero a causa del proceso contra sus cuñados se le impidió regresar al Perú, a pesar de su notoria fidelidad al rey. Sostiene que, a pesar de que el fiscal de la Audiencia de Lima absolvió a sus cuñados, lo mismo fueron expulsados a España, aduciendo:

... debían no obstante por insultantes é inquietos, ser separados de la tierra, sin seguirse para ello los medios ordinarios de proceso $[\ldots]$ Con cuio motivo vinieron a estos Reinos, sin tener consideración a que la separación de un individuo o familia de su Patria ${ }^{11}$, del Reino, y de todas las Indias al pretexto de infidencia al Soberano o del de inquietud, no puede evacuarse sin toda la debida audiencia en los Tribunales de Justicia, principalmente si hubiese de ser para siempre ... (“Memorial", f. 2v.)

Quienes acusan a los Ugarte eran sus "enemigos capitales" por emulación en los empleos y acciones políticas en los que habían intervenido y no justifica que el odio desatado por estas disputas recaiga sobre el cuñado de ellos, o sea, el mismo Campero. La solicitud para recuperar su cargo en

9 El texto de la Pragmática se puede consultar en la Novisima Recopilación (t. 4). El año correcto de la sanción de esta es 1774.

10 En ese momento Chucuito integraba el Virreinato del Río de La Plata.

11 Patria en este caso el Cuzco. Para los matices de este concepto, véase Chiaramonte. 
Chucuito se apoya en diversas leyes. "Tales son la 10. tit. $11^{12}$ y la 19. tít. $12^{13}$. y la 61. tit. $14^{14}$. lib. 10, la 61. tit. lib. $3 .^{.15}$ y la 18 y 20 tit. 8. ${ }^{\circ}$ lib.7..$^{\text {"16 }}$ ("Memorial", f. 3r.) de las leyes de Indias, así como la ley 5, título 24 de la Partida 4 de Alfonso el $\mathrm{Sabio}^{17}$, todas relativas a los problemas derivados de la extradición, como se puede ver en Las siete partidas.

Las tres primeras leyes de Indias se refieren a asuntos eclesiásticos y sus relaciones con el poder civil, y tienen el propósito de señalar los límites que la Corona imponía a los eclesiásticos cuando se entremezclan en la vida política y provocaban la formación de "bandos y parcialidades". Seguramente fueron citadas para descalificar al obispo Moscoso que por su controversia con Antonio Ugarte, se convirtió en uno de sus más feroces enemigos.

Las restantes leyes preservan los derechos y condiciones para extraditar a personas de las Indias, acción que se debe justificar ante el rey en persona, prescribiendo la intervención de los tribunales. No obstante, la última ley citada (20 tit. 8. lib.7) contiene una cláusula en la que se admite que aún si los tribunales han concedido el perdón, el destierro también es posible si existieran sospechas de actitudes que afectaran la paz pública.

12 Esta ley se refiere a situaciones derivadas de sedes vacantes; ordena que se evite dar órdenes perjudiciales al bien común o a los indios (Novísima Recopilación, t. 1, f. 51v.).

13 El enunciado es que "los predicadores no digan en el púlpito palabras escandalosas". Se refiere fundamentalmente a acusaciones contra el poder real, los ministros o justicias (Novísima Recopilación, t. 1, f.54v.).

14 Ley destinada a evitar que se produzcan escándalos cuando las órdenes religiosas realizan sus capítulos o asambleas periódicas (Novísima Recopilación, t. 1, f. 70v.).

15 Recomienda a los virreyes que cuando sea necesario desterrar a un vasallo "de aquellos reinos", lo hagan "habiendo procedido judicialmente, y nos remitan la causa fulminada para que Nos veamos si tuvieron bastantes motivos para esta resolución” (Novísima Recopilación, t. 2, f. 21r.).

16 Tratan sobre extrañar a una persona de las Indias. La ley 18 señala que tal medida no se tome sin causa justificada y la ley 20 que los virreyes y gobernadores guarden lo resuelto en la 61, título 3, libro 3 (ya citada por Campero) "y extrañen de sus Provincias a los que conviniere al servicio de Dios, nuestro Señor, y nuestro, paz y quietud pública, que no residan en aquellos Reinos, sin embargo de que hayan obtenido perdón de sus delitos, remitiéndonos la causa, para que examinemos su justificación" (Novísima Recopilación, t. 2, f. 297r.).

17 Se debería decir Alfonso X, en la época se contaban las dinastías de diferente manera. 
Es notable que Campero haya citado esa ley, porque en ella se apoyaron las autoridades metropolitanas: los Ugarte alteraron la paz pública, según el oidor Benito Mata Linares, el comandante Avilés — ambos enviados a Cuzco a raíz de la rebelión-, el corregidor de Cuzco y el virrey Theodoro Croix ${ }^{18}$. Estas leyes retoman los principios expresados en las Partidas (ley 5, título 24 de la Partida 4, citada por Campero), donde se sostiene que nadie puede ser extraído de su tierra sin justa razón y si no existieran pruebas de traición al rey. Agrega la ya mencionada Pragmática de Carlos III de 1774, insistiendo en que ante las complejas circunstancias de las sediciones, son los tribunales locales, en primera instancia, y luego los de la Corte a quienes compete la decisión y que esta no puede basarse en los caprichos de algunos funcionarios.

Estamos ante un ejemplo de la anfibológica interpretación de las leyes, en el que primaba el arbitrio del juez, según la escala de valores del patrón moral de cada época (Agüero). No obstante, citando la ley 20, título 8, libro 7, Campero la contradice pues, como lo dijo anteriormente, la decisión de extradición sólo correspondía a los tribunales y al rey. "Es pues contra toda legislación, y lo últimamente mandado la idea que propuso el comandante de las Armas de Cuzco de que no estando probado el delito se condenase à los Ugartes a que saliesen del Reino sin toda la debida justificación" ("Memorial”, f. 3r.; las cursivas son de la autora).

En suma, aun cuando sus cuñados se hubieran excedido en las palabras, todo debiera haber concluido en un apercibimiento o, cuanto más, en la expulsión de la ciudad o de la provincia, pero nunca con el terrible castigo de la extradición de su patria, ya que la ley de Indias $7^{a}$ tit. $4^{\circ}$ lib. 3, que cita textualmente ${ }^{19}$, sólo admite esta grave medida: "cuando haya positiva

18 Varios documentos ubicados en el Archivo General de Indias (C 29 y 30 ).

19 Esta ley garantiza la tranquilidad pública utilizando el recurso de la extradición, pero preservando la unidad de la familia: "Si sucediere que algunas personas inquietaren la tierra, Mandamos a los Virreyes y Presidentes Gobernadores, que por los mejores medios, que les pareciere y pudieran, las vayan sacando de aquella Provincia, y a sus hijos, hermanos y deudos, y a los demás, que hubiere seguido su parcialidad, y los acomoden en partes seguras, donde los tengan cerca, de modo que no se cause nota" (Novísima Recopilación, t. 2, f. 24r.). 
y calificada incorregibilidad". Si tal hubiera sido el caso, debieron de haber sido detenidos y encarcelados en el momento, cosa que no sucedió, y si existía sospecha los Ugarte pudieron ser obligados a lo sumo a permanecer en Lima bajo la vigilancia del virrey.

Campero enumera sus méritos como individuo — probablemente exagerados - en los diversos cargos asumidos y, sobre todo, en su actuación durante la rebelión, según él altamente valorados por las autoridades militares, por el virrey Jaúregui y el visitador Areche:

¿Será sospecha, venciendo ingentes dificultades ${ }^{20}$ ponerse en camino sin dar descanso â las fatigas de campaña, venir desde aquellas remotas tierras abandonando su Mujer e hijas para traer los Pliegos, y proporcionar el mas sentado acuerdo de las providencias que tuvo Vuestro Augusto Padre? ¿Será sospecha la reiterada elección que se hizo siempre de su persona por los primeros Gefes, para todos los gravísimos destinos que van expuestos? ¿Será sospecha haber su Mujer auxiliado con todas sus facultades, y con las vidas de su hijo y marido â los Gefes que dirigían nuestro exercito y al Excercito mismo? No Señor: Confianzas y sospechas no pueden ser, ni lealtad con recelos de deslealtad; mayormente cuando los servicios en el mismo caso en cuestión, destruien toda sospecha, y no haberse probado hecho alguno a favor de esta, en dos distintas $[\ldots]$ pesquisas, actuadas la primera por dos rectísimos Ministros, y la segunda por los mismos acusadores que lograron contra derecho, constituirse Jueces de sus propias delaciones. ("Memorial", f. 20)

A continuación destaca su privilegiado estatus social. Su genealogía familiar marca su lugar en el mundo, una prueba más de la vigencia de la sociedad estamental en el seno de una monarquía absoluta que él define como Estado.

\section{Competencias jurisdiccionales: civiles contra militares y Lima contra Cuzco}

Campero describe los desacuerdos entre el alcalde ordinario Gaspar Ugarte y el corregidor de Cuzco por la preeminencia en los asientos del Cabildo 
y con el comandante Avilés por asuntos de jurisdicción en caso de delitos cometidos por las tropas limeñas. Gaspar había alegado que se desconocía su competencia para ejercer justicia, y el comandante se sintió afectado por este reclamo. Ambas situaciones derivaron en mutuos insultos y provocaron las denuncias que iniciaron el proceso judicial.

Aquí aparecen los recelos del poder civil por la injerencia de los militares en asuntos políticos, tema sobre el que existe información contradictoria. El visitador Areche ${ }^{21}$, por ejemplo, critica duramente a los virreyes militares que no conocen las leyes ni saben aplicarlas; de ahí que reclame que la Corona envíe personas ilustradas para esos cargos. Juan Marchena (2005-2006), por el contrario, destaca la presencia de militares ilustrados que llegan a Perú en esos años y aunque Campero presenta un perfil más modesto, bien puede ser incorporado a ese grupo.

Campero tratará de desmontar capa por capa los sucesivos intentos hechos por los enemigos de la familia Ugarte, la mayor parte sin otro fundamento que las "pequeñas intrigas" de la política local. Se propone dejar al descubierto que la acusación de infidelidad fue la excusa para eliminar a personas que cuestionaban, entre otras cosas, el creciente militarismo de la política real. Según nuestro autor, las denuncias fueron escalando distintas escalas de gravedad: se iniciaron con una disputa por asientos en el Cabildo, continuaron con injurias y finalizaron con la acusación de infidelidad, que si se hubiera probado no necesitaban enmascararla con excusas banales. Su conclusión es la siguiente: "De esta naturaleza son las cosas que anima el odio mortal: un monstruo compuesto de muchos cuerpos distintos y aún varios entre sí, y cada uno sin sustancia, ni verdad" ("Memorial”, f. 8v.).

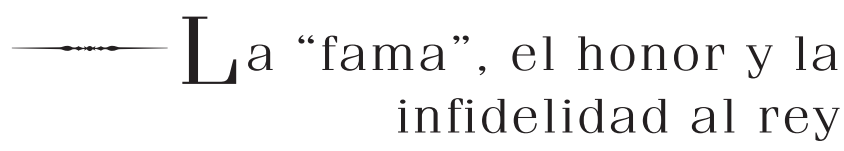

La enemistad, la reputación y la honra ocupan bastante espacio en el alegato de Campero. Se citan cartas de los denunciantes (entre ellos del obispo) y de sus respectivos allegados dirigidas al virrey sobre los "escándalos" en 
los monasterios o por otros asuntos relacionados con sus cuñados. Citando las leyes 22, título 16, partida 3a, y 2a, título 17, partida 6a, se afirma: "hay enemistad grave siempre que alguno se tiene de otro menguado en la honra: siempre que alguno acusa a otro por su propio interés e injuria, o siempre que alguno se da por enemigo conocido, demostrándose que es tal por algunos hechos o palabra" ("Memorial", f. 6v.).

En efecto, en la partida 3a, ley22, título 16, se expresa que aquellos quienes demuestran enemistad con la persona juzgada no deben ser testigos en un pleito: "Ca por cualquier destas maneras que aya enemistad entre los omes, non deven testiguar los unos contra los otros, en quanto la enemistad durare" (Las siete partidas 184); y en la partida 7a, ley 27, título 1, se aclara que cuando el acusador es declaradamente enemigo del acusado, el rey se debe abstener de promover la pesquisa (Las siete partidas 186). La argumentación frente a estos incidentes es directa y apasionada. Después de enunciar con cierto detalle los enfrentamientos de Gaspary de Antonio, Campero clama:

¿Puede ser mayor el incendio interior de estos Jefes? ¿Mas su venganza? ¿Mas su enemistad? Esta no es una enemistad sacada por conjetura ó probable. No es una enemistad deducida de acaecimientos atrasados. [... [ ¿Y una sindicación de esta especie podía ser materia de juicio? ("Memorial", ff. 6v-7r; las cursivas son de la autora)

Lamenta la deshonra que implica estar obligados a permanecer perpetuamente en España, acusados del parentesco de los Ugarte con Túpac Amaru, y defiende la pureza de sangre de dicha familia, originaria de las montañas de Vizcaya y Extremadura. El exilio por causa de sedición o traición al soberano es doblemente deshonroso, según lo establecido por la ley $5^{a}$ título 24, partida 4 (“Memorial”, f. 14v.). Aquí su discurso es enfático y apasionado, pero es necesario notarlo, no es vindicativo, no solicita castigo para sus enemigos; su alegato sólo apunta a la defensa de su familia y de sí mismo. Los desencuentros que se produjeron entre los Ugarte y los funcionarios reales en los meses de abril y mayo de 1783 no justifican que la venganza de los ofendidos alcanzara tanta agresión. En cuanto a su persona, Campero no admite que sólo por ser el marido de la hermana de los inculpados haya sido privado de su puesto y obligado a vivir apartado de su familia, sin cargo alguno en su contra. 
En su opinión, la Audiencia de Lima no debió iniciar el proceso cuando no existía una denuncia formal y probada de infidelidad y las denuncias derivaban de conflictos personales de intereses y preeminencias simbólicas, tal vez expuestos (admite) en disputas apasionadas, pero de ninguna manera en una conducta adversa a la potestad real. Si este fuera el caso, el comandante tendría que haber presentado una "formal delación" en el momento preciso y no tres años después que Túpac Amaru dirigiera su carta a Antonio y a Gabriel Ugarte. Por el contrario, lo hizo a causa de las injurias que había recibido pero, según la "Ley $3^{a}$ tit. 9 part. $7^{\text {a", }}$ que trata de la deshonra que un hombre hace a otro por "cantigas o por rimos", manifestados en palabras o escritos que infaman a los hombres. Esta conducta debe ser probada fehacientemente, caso contrario "quedará infamado el que acusa" (Las siete partidas 332).

El tema de la infidelidad, no probada, es el motivo por el cual los Ugarte fueron expulsados. Campero trata de probar que esta acusación es falaz al analizar la carta enviada por Túpac Amaru. Insiste: ni Antonio ni Gabriel se sintieron obligados a cumplir con lo solicitado a pesar de las amenazas con las que finalizaba la misiva. Otros cuzqueños recibieron cartas similares, pero no fueron molestados por ello, y se pregunta: “ipor qué el Visitador [Areche] no investigó a fondo los vínculos que podían existir entre los criollos y el curaca de Tinta? Si esto se hubiera hecho, no cabría lugar para las sospechas". En efecto, como lo señala en su escrito, nuestra investigación ha constatado que no existían pruebas sobre estas conspiraciones en los papeles de Areche ${ }^{22}$.

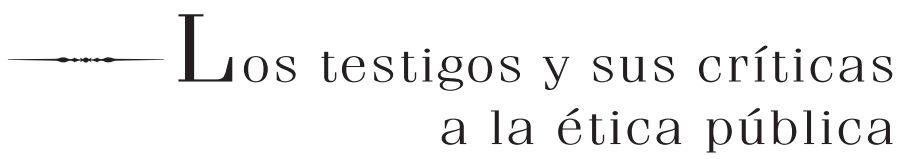

Campero recusa los testigos propuestos por los denunciantes apelando a

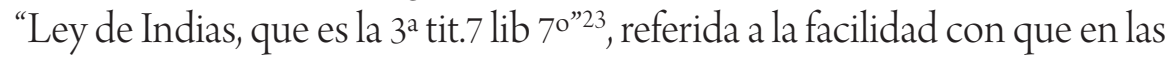

22 Extracto del proceso a los hermanos Ugarte (AGI, C 30).

23 Campero debió cometer un error al citar esta ley, porque su texto, dedicado a problemas de cárceles, no se ajusta en nada con la argumentación vertida en el Memorial. 
tierras de ultramar se encuentran falsos testigos. En estos párrafos manifiesta, en términos muy duros, sus recelos sobre la conducta de los habitantes de estas tierras, fueran criollos o peninsulares. Opiniones reiteradas en muchos de sus escritos. El menosprecio a los criollos era compartido por muchos de sus contemporáneos y, aunque de larga data, se agudizó entre los ilustrados.

Fundamenta estos argumentos, recurriendo a ley 2, título 1 de la partida $7^{\mathrm{a}}$, en la que se enumeran quiénes están impedidos de acusar, entre ellos los magistrados. Tampoco admite que en las denuncias se mezclen las emociones y subjetividades personales, tal como hicieron los testigos, a los que califica de "enemigos capitales" de la familia Ugarte. Aunque algunos de ellos pudieron haber obrado de buena fe, a la mayoría los sindica como "mal contentos, alucinados, y enemigos; otros viles, ebrios, jugadores y de pública mala nota” ("Memorial”, f. 12r.).

En su opinión, la mayor parte de los testimonios se basan en rumores, en conversaciones que transcurrían al azary todo fue un asunto de "sospecha de sospechas de sospechas”. Recuerdala intervención delfiscal de la Audiencia de Lima, quien acusó a varios de los testigos por falsarios, pues no podían probar sus dichos ni habían delatado en su momento el supuesto delito de infidelidad. Sostiene que para forzar las denuncias se recurrió a viejos pleitos de los Ugarte, expurgando todos sus antecedentes con verdadera saña.

\section{Parcialidades y facciones}

La formación de "parcialidades y facciones" es un tema netamente antropológico, por cuanto permite analizar la capacidad de los individuos para organizarse por fuera de las instituciones formales. Veamos como argumenta Campero en este punto:

[La ley de Indias $7^{\circ}$ tit. $4^{\circ}$ lib.3], habla expresamente de unos hermanos y deudos que sigan parcialidad, confederándose a unos propios hechos con uniforme espíritu, que es lo que se llama concurso sedicioso a lo menos ha de 
resultar de diez personas en una propia acción, para que se tenga y se juzgue por tal. ("Memorial", f. 14r.)

En su opinión, los Ugarte no formaban una facción, porque "no son capaces de parcialidad, no siendo los hermanos mas unidos”. Tampoco le compete a él ni a su mujer tal figura, porque nunca han estado demasiado ligados con los tres hermanos, ya que han vivido 19 años alejados de Cuzco, en distintos empleos. Agrega que regresó a esa ciudad cuando la rebelión se había iniciado y destaca que su designación como gobernador de Chucuito lo ponía bajo la jurisdicción del Virreinato del Río de la Plata, mientras que Cuzco pertenecía a la de Perú.

En efecto, durante nuestra investigación no hemos encontrado pruebasfehacientes de un "concursosedicioso" entrelos hermanosnide ellos con otros miembros de la élite cuzqueña, pero sí indicios de acciones en favor de la causa de los criollos, en particular durante la abortada "conspiración de los plateros" de Cuzco, a comienzos de 1780 . O sea, pese a la firme defensa de Campero para borrar cualquier sombra de infidelidad en la conducta de sus cuñados, en Cuzco existía, y sobre todo entre las autoridades, la fuerte sospecha de que los Ugarte integraban el grupo criollista opuesto a las reformas.

Durantelos disturbios en el monasteriode Santo Domingo, en los que intervino Antonio, se acumularon algunas armas para impedir la liberación de uno de los frailes encarcelado por el prior, hecho interpretado como indicio de un proyecto de conspiración criolla contra el rey ${ }^{24}$.Ensuma, el clima de sospechas se fundaba en la reiteración de enfrentamientos de las autoridades con el sector criollo en varias ciudades andinas (Arequipa, Oruro y Cuzco).

\section{F amilia y parentesco}

Las relaciones de parentesco y la estructura de autoridad dentro de la familia es otra de las grandes preocupaciones de la antropología. En este tema 
es interesante observar que Campero argumenta utilizando citas bíblicas, tal como era habitual en la época (Padgen; Guerra):

Nada es mas repetido en las Divinas letras sino que el Alma delinquió sea la que muera, y sufra la pena: Que aun el hijo no lleve la iniquidad de su Padre, y entre los hermanos Cain, Abel, Esau, y Jacob, el uno fuese maldito de Dios, y el otro bendito; el uno objeto de eterno amor, y el otro de perpetuo aborrecimiento. Por la Ley $9^{a}$ tit. 32 part. $7^{a}$ se dispone que por el yerro que el Padre hiciese no deben recibir pena los hijos, ni los otros Parientes, ni la Mujer por el Marido, respecto de que la pena debe ceñirse á los Malhechores. Y aunque tiene la restricción del Crimen de Traición, la propia Ley se limita únicamente â los hijos, los cuales entienden los Autores son los nacidos después de haberse perpetrado.

La Ley de Castilla que es la decima tit. $1^{\circ}$ lib $5^{025}$ expresamente habla del Crimen de lessa Majestad cometido por el marido ó la mujer declarando no perjudicar á su consorte. Y tiene mas fuerza cuando el sindicado no es el Marido, sino la Mujer, respecto de que esta está sujeta á aquel, y no el Marido á la Mujer; de quien por todo derecho Divino y positivo es su Cabeza y lleva la dirección de la familia: Por esa la Ley $2^{a}$ tit. $2^{\circ}$ partida $7^{a}$ restringe la infamia á los hijos del Traidor que sean varones, exceptuando de ella á las Mujeres, por el fundamento que no es de temer que estas tomen la voz, ni se introduzcan en las casas de los hombres. Con que si al exponente se toma por ser casado con D. Juana Ugarte, es violentísima la sospecha, como que por Mujer por si misma, aunque hubiese sido culpado su Padre, no puede ser capaz de participación alguna, como lo presume y advierte la citada Ley real.

Campero se apoya en las partidas (Ley 9a, título 32, y ley 2, título 2 de la partida $7^{2^{26}}$ ) para desligar su responsabilidad personal respecto a los

25 No hemos podido identificar las leyes citadas en estos párrafos.

26 La ley 2, título 2 de la Partida $7^{\mathrm{a}}$ expresa textualmente: "Cualquier ome que hiciese alguna cosa a la manera de traición, $[\ldots]$ o diere ayuda o consejo que la hagan debe morir por ello; e todos sus bienes deben ser de la Cámara del Rey, sacando la dote de su mujer y los deudos que hubiese a dar que hubiese manlevado hasta el día que comenzó a andar en la traición: e demás todos sus hijos que sean varones deben fincar por enfamados para siempre de manera que nunca puedan haber honra de Caballería, ni de Dignidad, nin oficio ni puedan heredar a pariente que hayan nin a otro extraño que los estableciese por herederos ni puedan haber las mandas que les fueren fechas. Esta pena deben haber por la maldad que hizo su padre. Pero las fijas de los traidores bien pueden heredar hasta la cuarta parte de los bienes de sus madres. Esto es porque no debe ome asmar que las mujeres ficiesen traición, nin se metiesen en esto tan de ligero a ayudar a su padre como los varones e por ende non deben sufrir tan grande pena como ellos." (Las siete partidas). 
supuestos delitos de sus cuñados; no obstante, admite que se fijen otras pautas para casos de delitos de lesa majestad que puedan afectar a los hijos varones. Cita textualmente la ley 9, título 32 de la partida $7^{\text {a }}$, y agrega que la infamia sólo afecta a aquellos hijos nacidos después de haberse perpetrado la traición ("Memorial", f. 17r). Sin embargo, como la ley 2, título 2, lo señala, su argumento es que la infamia no podía llegar a su persona por intermedio de su mujer, dada que por su condición natural las mujeres están bajo la tutela de sus padres o maridos.

Nos interesa destacar que nuestro personaje no pone en duda que los delitos cometidos por una persona pueden afectar al menos a una parte de la familia. O sea, comparte la noción de la identidad adscriptiva al parentesco, consagrada en las partidas del siglo XIII y todavía vigente a fines del siglo XVIII. Esta es una prueba irrefutable de que el individualismo iluminista no ha permeado todavía al grueso de la sociedad y que permanece concentrado en el nivel de los teóricos e intelectuales. Para reforzar su alegato, Campero hace una genealogía de la sospecha y sostiene que la que recae sobre él es "una tercera nieta" de sospechas y, por lo tanto, carece de identidad delictiva y que aun cuando esa culpa hubiera recaído sobre el padre de doña Juana Ugarte, no podría alcanzarlo puesto que no es hombre dominado por su mujer.

Por otra parte, las leyes del tit. $3^{\circ}$ lib. $7^{\circ}$ de Indias obligan a los españoles a hacer vida marital con la esposa, y la situación en la que él se encuentra se asemeja a un divorcio forzado, o bien sería el caso que doña Juana y sus hijas ${ }^{27}$ fueran obligadas, "contra su libertad" a residir en España (Novísima recopilación, t. 2, ff. 281r.-283r.). Este argumento denota, muy sutilmente, la fuerza del afincamiento de los criollos de tercera generación en tierras americanas.

Para tomar determinaciones tan graves se debe recurrir a los tribunales para asegurar "armonía, orden, esplendor y esencia del Estado”. Aquí Campero utiliza el concepto "moderno" de Estado, como un organismo 
constituido por reglas universales que garantizan la vida armónica de la comunidad, de sus derechos y sus relaciones con las autoridades ${ }^{28}$. Todo lo expuesto es, según su criterio, motivo suficiente para que se lo libere de la nota de infamia que ha caído sobre él y su familia y se le permita recuperar su puesto como gobernador de Chucuito.

\section{Hpílogo}

Como lo expresa Campero, la condena al exilio se basó en sospechas de sospechas de infidelidad al monarca, construidas a partir de indicios y conjeturas. El virrey Croix ${ }^{29}$ consideró que la acumulación de indicios - como lo admitía la doctrina jurídica (Agüero) — justificaba que los Ugarte fueran apartados de Cuzco, ciudad amenazada por una alianza de criollos e indios. La dudosa fama de los Ugarte - que aunque considerado como indicio remoto era jurídicamente aceptable — fue tema reiterado en los interrogatorios, como lo comprobamos al analizar los autos del proceso.

Por el momento no hemos hallado en los archivos una respuesta a la solicitud de Campero ni un reconocimiento de la (supuesta) injusticia de la que había sido víctima. Los Ugarte reclamaron insistentemente autorización para regresar a Perú, y aunque no tuvieron éxito, se les compensó con pensiones y cargos menores para que subsistieran en España. Nunca lograron que se reivindicara su honor. Creemos que todos murieron es España. Campero falleció en Madrid, el $1^{\circ}$ de julio de 1791.

El Memorial escrito por Campero, con el auxilio de un letrado o sin este, permite observar el grado de inserción de estos militares ilustrados en el sistema jurídico. Se destaca también por un discurso dramatizado donde juegan las pasiones de los individuos, expresadas con total espontaneidad. Lo más importante, sin embargo, es que en un solo documento se pudieron identificar todas las líneas de fricción que atravesaban las instituciones y a la sociedad peruana de la época.

28 Para el concepto de Estado en este período, véase Chiaramonte.

29 Croix a Gálvez (AGI, C 30, nº 17). 


\section{- Bibliografía}

\section{Fuentes PRIMARIAS DE ARCHIVO}

Archivo General de Indias, Sevilla, España (AGI)

Cuzco (C) 29, 30.

Lima (L) 1086.

Archivo Nacional del Perú, Colecciones documentales (ANP, CD).

"Memorial enviado por Juan Manuel Campero al rey por el asunto de sus cuñados Ugarte". Archivo General de Indias (AGI), Sevilla. Estado 77, no 86.

\section{FUENTES PRIMARIAS IMPRESAS}

Las siete partidas del sabio rey don Alfonso el IX (sic) con las variantes de más interés, y con la glosa del Lic. Gregorio López del Consejo Real de Indias de S. M. Barcelona: Bergnes, 1843.

Novísima recopilación de las leyes de España. Códigos españoles, concordados y anota-dos. t. 4, 7-10. Madrid: Imprenta de la Publicidad a cargo de D. M. Rivadenei-ra, 1850.

\section{Fuentes secundarias}

Agüero, Alejandro. "Indicio/s". Diccionario histórico judicial. México: Corte Suprema de México, 2008.

Bunster, Cora y Ana María Lorandi. "El fantasma del criollismo después de la rebelión de Túpac Amaru”. Histórica 11 (2006): 99-136.

Carrió de la Vandera, Alonso (Concolocorbo). Reforma del Perú. 1782. Trascripción y prólogo de Pablo Macera. Lima: Universidad Mayor de San Marcos, 1966.

Céspedes del Castillo, Guillermo. "Lima y Buenos Aires". Anuario de Estudios Americanos, 3(1946): 369-874.

Chiaramonte, José Carlos. Nacióny Estado en Iberoamérica. Buenos Aires: Sudameri-cana, 2004.

Escandell-Tur, Neus. Producción y comercio de tejidos coloniales: los obrajes y chorrillos del Cusco 15701820. Cusco: Centro de Estudios Regionales Andinos “Bartolomé de Las Casas", 1997.

Fisher, John. El Perú borbónico: 1750-1824. Lima: Instituto de Estudios Peruanos, 2000.

Guerra, Françoi-Xavier. "Políticas sacadas de las Sagradas Escrituras': la referencia a la Biblia en el debate político (siglos XVII a XIX)". Élites intelectuales y modelos colectivos: mundo ibérico (siglos XVI-XIX). Eds. Mónica Quijada y Jesús Bustamante. Madrid: Consejo Superior de Investigaciones Científicas, 2000. 155-98.

Halperín Donghi, Tulio. Reforma y disolución de los imperios ibéricos 1750-1850. Madrid: Alianza, 1985.

Hespanha, Antonio. La gracia del derecho: economía de la cultura en la edad moderna. Madrid: Centro de Estudios Constitucionales, 1993.

Lewin,Boleslao. Larebeliónde TúpacAmaruy losorígenes delaIndependenciadeHispanoamérica. Buenos Aires: Sociedad Editora Latinoamericana, [1943] 2004. 
Lorandi, Ana María. Poder central, poder local: funcionarios borbónicos en el Tucumán colonial. Un estudio de antropología histórica. Buenos Aires: Prometeo, 2008.

Marchena, Juan. "Al otro lado del mundo: Josef Reseguín y su 'generación ilustrada' en la tempestad de los Andes. 1781-1788". Anuario de Estudios Bolivianos 12 (2005): 43-111.

Mazzeo, Cristina, coord. Los comerciantes limeños a fines del siglo XVIII: capacidad y cohesión de una élite 1750-1825. Lima: Pontificia Universidad Católica del Perú, 1999.

Mörner, Magnus. Perfil de la sociedad ruraldel Cuzco a fines de la Colonia.Lima: Universidad del Pacífico, 1978.

O’Phelan Godoy, Scarlett. "Aduanas, mercado interno y élite comercial en el Cusco: antes y después de la gran rebelión de 1780”. A puntes 19 (segundo semestre, 1986): 53-72.

----. Un siglo de rebeliones anticoloniales: Perú y Bolivia 1700-1783. Cuzco: Centro Bartolomé de las Casas, 1988.

----. "Entre Gálvezy Areche: el factor acumulativo de la presión fiscal y la gran rebelión de 1780". Historias paralelas: actas del Primer Encuentro de Historia Perú-México. Ed. Margarita Guerra Martinière. Lima; México: Pontificia Universidad Católica del Perú; El Colegio de Michoacán, 2005.213-32.

Padgen, Anthony. "Dispossesing the Barbaian: The Language of Spanish Thomism and the Debate over the Property Rights of the American Indians". The Languages of Political Theory in Early-Modern Europe. Ed. Anthony Padgen. Cambridge: Cambridge University Press, 1990.

Salas de Coloma, Miriam. Estructura colonial del poder español en el Perú: Humanga (Ayacucho) a través de sus obrajes, siglos XVI-XVIII. Lima: Pontificia Universidad Católica del Perú, 1998.

Smietniniansky, Silvina. "El juicio de residencia como ritual político en la colonia (Gobernación del Tucumán, siglo XVIII)”. Memoria Americana 15 (2007): 71-102.

Tambiah, Stanley. Culture, Thought and Social Action. Cambridge: Harvard University Press, 1985.

Tandeter, Enrique y Nathan Wachtel. Precios y producción agraria: Potosí y Charcas en el siglo XVIII. Buenos Aires: CEDES, 1983.

Tau Anzoátegui, Víctor. "La costumbre jurídica en la América española: siglos XVI-XVIII". Elpoder de la costumbre: estudiossobre el derecho consuetudinario en América española hasta la Emancipación, por Tau. 1986. Buenos Aires: Instituto de Investigaciones de Historia del Derecho, 2001.85-159.

Walker, Charles. De Túpac Amaru a Gamarra: Cuzco y la formación del Perú republicano 1780-1840. Cuzco: Centro Bartolomé de las Casas, 1999.

Fecha de recepción: 20 de febrero de 2009.

Fecha de aprobación: 16 de marzo de 2009. 